CAN PERformance of INDigenous Factors

INFLUENCE GROWTH AND GLOBALISATION?

Kui-Wai Li, Iris A.J. Pang and Michael C.M. Ng

CSGR Working Paper No. 215/07

January 2007 


\title{
Can Performance of Indigenous Factors Influence Growth and Globalisation?
}

Kui-Wai Li, Iris A.J. Pang and Michael C.M. Ng

CSGR Working Paper 215/07

January 2007

\begin{abstract}
:
This paper employs a total of thirty four openness factors and indigenous factors to construct two indicators for 62 world economies for the period 1998-2002. While most globalization studies concentrated on openness factors, regression estimates and simulation studies show that sound performance in indigenous factors are crucial to an economy's growth and globalization. Empirical evidence shows that an optimal performance in indigenous factors can be identified, and that successful globalized economies are equipped with strong performance in their indigenous factors.
\end{abstract}

\section{Keywords:}

Globalization, indigenous factors, openness, world economies

\section{Acknowledgements:}

We would like to thank Barbara Stallings, Neantro Saavedra-Rivano, Gianluca F. Grimalda, Peter J. Newell, participants in the APEC Study Center Consortium annual meeting in Ho Chi Ming City, Vietnam, in May 2006, and two anonymous referees for their comments on the earlier version of the paper. We are grateful to the funding support from the Faculty of Business, City University of Hong Kong. The authors are solely responsible for the remaining errors.

\section{Contact Details:}

Kui-Wai Li

Department of Economics and Finance, City University of Hong Kong

Tat Chee Avenue, Hong Kong.

E-mail: efkwli@cityu.edu.hk 


\section{CAN PERFORMANCE OF INDIGENOUS FACTORS INFLUENCE GROWTH AND GLOBALIZATION?}

\section{Introduction}

Studies on globalization show that factors that determine an economy's performance in globalization included trade and income, inequality and poverty, distortion in the factor market and child labor (Subramanian and Wei 2003; Winters 2002; Deardorff and Stern 2002; Bhagwati 2002; 2004; Aisbett 2005; Frankel 2000; Falvery and Kreickemeier 2005 and Edmonds and Pavcnik 2002). While most pro-globalization advocates (for example, Feldstein 2000) examined the impact of external or openness factors, anti-globalization advocates focused on economic sectors that have lost out in the process of globalization (Wallach and Woodall 2004; Stiglitz 2002). Fischer (2003) noted that globalization is much more than an economic phenomenon and has non-economic consequences.

Globalization indices have popularly been constructed to rank different world economies using either a non-parametric approach as in Kearney (2005) or the principal component analysis as in Andersen and Herbertsson (2005), Heshmati (2006) and Derher (2006). One commonality in these index construction is the employment of a number of external economic or openness factors, typically trade and foreign direct investment, that are grouped into several categories. Only a few domestic or indigenous factors are included in the calculation of a single globalization index.

Although the performance of the external economy is usually seen from such openness factors as the level of international trade, capital inflow and the number of tourists, the link between these openness factors and an economy's performance in the 
global community, however, depends also on how the domestic sector performed. While a more matured capital market, for example, will facilitate a greater capital flow, a more transparent, corruption-free investment environment, for example, could attract more foreign direct investment. Indigenous factors in an economy can complement the successful performance of economic openness.

This paper distinguishes indigenous factors from the openness factors. Using available data from 62 world economies for the period 1998-2002, two separate indices are constructed for openness factors and indigenous factors. Regression analysis is conducted to show how the two types of factors can impact on economic growth. To show the importance of indigenous factors and how they can exert independent influence on growth and performance in globalization, regression analysis is used to find the optimal level of performance in an economy's indigenous factors. Lastly, the 62 world economies are mapped according to their performance in the openness factors and indigenous factors. The result shows that economies will have to achieve a certain level in their performance of the indigenous factors before they can take advantage of economic openness.

Section II uses an improved method to work out the two indices for the openness factors and indigenous factors, and the ranking of the 62 world economies. Section III gives the regression estimates, while section IV compiles an optimal level of performance in an economy's indigenous factors and a simulation study is conducted to show how the 62 world economies performed in the two types of factors. Section $V$ concludes the paper. 


\section{The Two Indicators}

In constructing the globalization index, Kearney (2005) has grouped openness factors into four categories of economic integration, technological connectivity, personal contacts and international engagement. We follow this classification but improve the list of openness factors by incorporating the pattern of external trade of an economy in two aspects. Namely, while an economy's inter-industry trade is traditionally based on comparative advantage, an economy's intra-industry trade reflects its pattern of foreign direct investment and availability of technology. Trade statistics are post-trade data that reflect the outcome of trade policies. The performance of inter-industry trade can be seen from an economy's revealed comparative advantage $(R C A)$ index (Balassa 1965; 1977; 1979; 1986). ${ }^{1}$ When the value of $R C A_{i t, g}$ exceeds unity, economy $i$ is said to have a revealed comparative advantage in good $g$ at time $t$. The total number of export industries of individual economies with revealed comparative advantage greater than unity are selected and normalized (NRCA) to form an indicator for the economy's inter-industry trade performance $\left(T R C A_{i t}\right) .^{2}$

In intra-industry trade, economies export and import the same good or service in a given period. Intra-industry trade reflects more on the varieties of goods the economy enjoys due to industrial diversity and technological advancement than simply on trade

\footnotetext{
1 The RCA index can be calculated as: $R C A_{i t, g}=\left(\left(X_{i g} / X_{w g}\right) /\left(X_{i} / X_{w}\right)\right)_{t}$, where $X_{i g}$ denotes economy i's export of commodity $g, X_{w g}$ is world export of commodity $g, X_{i}$ is economy i's total export and $X_{w}$ is total world exports, where $i=1, \ldots, N, \quad t=1, \ldots, T$ and $g=1, \ldots, G$.

${ }^{2} T R C A_{i t}=\left(N R C A_{i} / \operatorname{MAX}_{i}\{N R C A\}\right)_{t} \cdot$
} 
flows based on comparative advantages. The extent of global economic integration through market structure and industry pattern can be seen from the level of intra-industry trade that also reflected the outcome of investment by multinational enterprises. The intra-industry trade index (IIT) can be calculated as:

$$
I I T_{i t}=\left(\sum_{j=1}^{n_{j}}\left\{\left[1-\sum_{g} X_{i j, g}-M_{i j, g} \mid / \sum_{g}\left(X_{i j, g}+M_{i j, g}\right)\right] * 100\right\} / \operatorname{MAX}_{i}\left\{\sum_{j=1}^{n_{j}}\left(\left[1-\sum_{g} X_{i j, g}-M_{i j, g} \mid / \sum_{g}\left(X_{i j, g}+M_{i j, g}\right)\right] * 100\right)\right\}\right)_{t},
$$

where $X_{i j, g}$ is the export value of good $g$ from country $i$ to country $j, M_{i j, g}$ is the import value of good $g$ to country $i$ from country $j$, and $n_{j}=$ total number of economy_is trading partners. Equation (1) shows the weighted average of individual industry indices, where the weights are the shares of industries in total trade. ${ }^{3}$

The data used in the construction of the Openness Factors Indicator (OFI) come from 17 external economic openness factors grouped under six categories. There are few exceptions. For example, Hong Kong has little international engagement in government transfer and financial contribution to the United Nations Security Council missions. Although the intention is to obtain as large a number of factors as possible, the data are more constrained in the construction of the Indigenous Factors Indicator (IFI). Data on a total of 17 indigenous factors are classified into three broad categories. While the first category of institutional establishment is considered as proxy measures for civility, security and protection of individuals, the other two categories provide indicators on the

\footnotetext{
3 The intra-industry trade index is compiled using the UN Comtrade Database, SITC Rev.3 (UN Comtrade, 1998-2002), for all the 62 economies with all commodities up to two-digit level.
} 
quality of life. Table 1 summarizes the categories of openness factors and indigenous factors and the data sources.

Table 1 The Classification of Openness Factors and Indigenous Factors

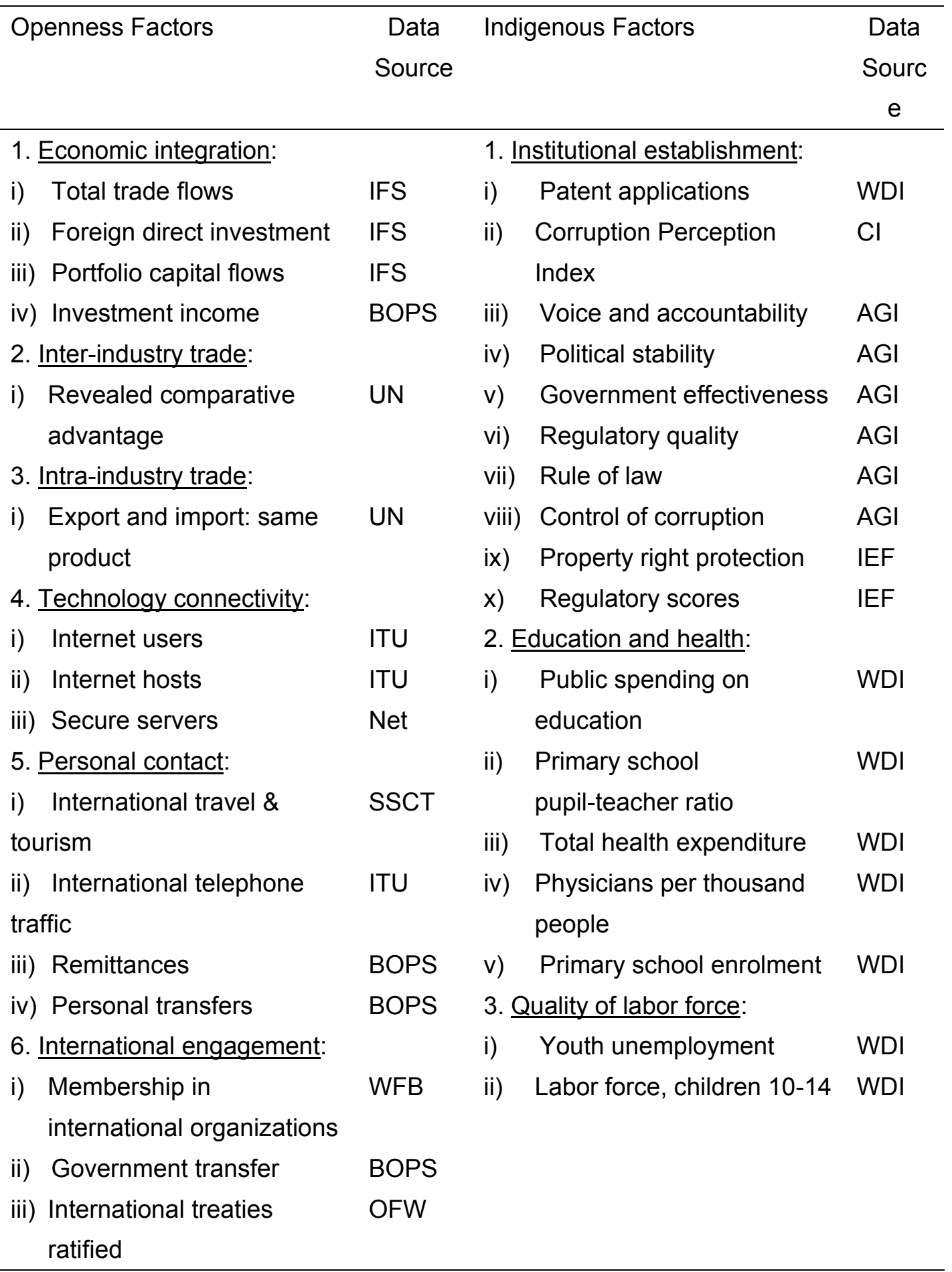


iv) Personnel and financial UNDPI

contribution to United

Nations Security Council

missions

Notes:

IFS = International Financial Statistics, International Monetary Fund;

BOPS = Balance of Payment Statistics, United Nations;

$\mathrm{UN}=$ United Nations Comtrade, United Nations;

ITU = International Telecommunication Union Database, International

Telecommunication Union;

Net $=$ Netcraft Secure, International Telecommunication Union;

SSCT = Server Surveys Compendium of Tourism Statistics, World Tourism

Organization;

WFB = The World Factbook, Central Intelligence Agency;

OFW = Official websites of selected basket of treaties;

UNDPI = United National Development Program Indicators, United Nations;

WDI = World Development Indicators, World Bank;

$\mathrm{Cl}=$ Corruption Index 1996-2002, Transparency House;

AGI = Aggregating Governance Indicators 1996-2004, World Bank;

IEF = Index of Economic Freedom, Heritage Foundation.

A total of 62 world economies have data on all or most of the openness factors and indigenous factors. Data for the three years in 1998-2001 are complete, while some 2002 data are either provisional or unavailable. Both the openness and indigenous factors are normalized on a yearly basis, as suggested in Lockwood (2004), before they are used to construct the $\mathrm{OFI}$ and $I F I .^{4}$

We apply the principal component analysis (PCA) to the indicators yearly. There

\footnotetext{
4 The normalization formulas for the high and low value variables that represent a higher degree of openness (in OFI) and a more advanced indigenous environment (in IFI), respectively, are:

$V_{i t}=\left(v_{i}-\min \left\{v_{1}, \ldots, v_{N}\right\} /\left\{\max \left(v_{1}, \ldots, v_{N}\right)-\min \left(v_{1}, \ldots, v_{N}\right)\right\}\right)$, and

$V_{i t}=\left(\max \left\{v_{1}, \ldots, v_{N}\right\}-v_{i} /\left\{\max \left(v_{1}, \ldots, v_{N}\right)-\min \left(v_{1}, \ldots, v_{N}\right)\right\}\right)_{t} . V_{i t}$ is variable $V$ of economy $i$ at time $t$.
} 
are several advantages in using the PCA method. Firstly, since these indicators are likely to be correlated, the PCA reduces these indicators to fewer variables that capture the maximum variation. Secondly, the PCA method can commensurate on the different measurement units of these indicators. Most importantly, the PCA method gives data-driven weights to the indicators that form the ultimate principal components. The principal components are extracted from the correlation matrix of the variables, in a way that they accounted for the highest percentage of variation. The PCA is applied to each individual year instead of applying one PCA to the whole sample period. This has the advantage of incorporating various changes in the sample period, and can eliminate the impact of a sudden change in any particular year that could affect other sample years.

We adopt a latent variable model and postulate that the indicator is linearly dependent on a set of observable factors $(V)$ and an error term (Rencher 2002). The principal components (PCs) are computed from the following procedure:

$$
\left\{\begin{array}{c}
P C_{1}=\alpha_{11} V_{1}+\cdots+\alpha_{1 \Psi} V_{\Psi} \\
P C_{2}=\alpha_{21} V_{1}+\cdots+\alpha_{2 \Psi} V_{\Psi} \\
\vdots \\
P C_{L}=\alpha_{L 1} V_{1}+\cdots+\alpha_{L \Psi} V_{\Psi}
\end{array},\right.
$$

where $\alpha_{11}, \alpha_{12}, \cdots, \alpha_{1 \Psi}$ are elements of eigenvector $\alpha_{1}=\left\{\alpha_{11}, \cdots, \alpha_{1 \Psi}\right\}$, and there are a total of $\underline{L}$ eigenvectors, which are determined by the data. A total of $L$ principal components are computed using successive eigenvectors elements, $\alpha_{1}, \alpha_{2}, \ldots, \alpha_{L}$, corresponding to the largest $L$ eigenvalues, $\lambda_{1}>\lambda_{2}>\cdots>\lambda_{L}$, of the factor correlation matrix. The first principal component, $P C_{1}$, of the linear combination with maximal 
variance becomes our OFI, which is then normalized or scaled. ${ }^{5}$ The scaled OFI will take a value of unity when an economy has the best performance in its external environment. The same procedures are applied to the construction of the IFI.

In constructing the two indicators, the missing values are replaced by their nearby means. ${ }^{6}$ Different weightings are generated from a corresponding principal component analysis for economies that an entire series of a factor is missing. The methodology is an improvement on Anderson and Herbertsson (2005) and Dreher (2006). Andersen and Herbertsson (2005) used a single principal component analysis for all the data in their sample period of 1979 to 2000 , and they provided rankings of economies according to the factor scores for each year generated by pooling the years over the sample period. However, taking Lockwood's (2004) suggestion on normalization, the problem of the methodology in Anderson and Herbertsson (2005) is that the change in the ranking of one economy in a specific year would change the rankings of other economies over the whole sample period. Dreher (2006) used weightings of principal component analysis from year 2000 for the calculation of indices for each single year from 1970 to 2000 . The principal component analysis is meant to give weightings that maximize the variance of the indices, but if weightings generated in 2000 are used for the indicator of all preceding years, the maximum variance effect is lost and the principal component analysis would seem meaningless.

Table 2 gives the five-year (1998-2002) average of the OFI and IFI indicators. The

${ }^{5}$ Scaled $O F I_{i t}=\left(O F I_{i}-\min _{i}\{O F I\} / \max _{i}\{O F I\}-\min _{i}\{O F I\}\right)_{t}$

${ }^{6}$ In the Openness Factors Indicators, the maximum number of missing economies in the 1998-2002 sample periods is 4, and their percentage ranged between $5.9 \%$ and $11.8 \%$. For the Indigenous Factors Indicator, the corresponding figures for the maximum number of missing economies are 40 , and the percentage ranged between $5.9 \%$ and $35.3 \%$. 
ranking based on the five-year average shows that the top 10 economies in the two indices are mainly advanced economies in North America and Western Europe. Most of the remaining European Union economies are included when the scores are extended to the top 20. Singapore and Hong Kong are the only two Asian economies in the top 20 of both indicators. We observe that an economy can vary between the two indicators. For example, Japan ranked $18^{\text {th }}$ in the $I F I$, but ranked $26^{\text {th }}$ in the OFI, while Indonesia ranked $44^{\text {th }}$ and $55^{\text {th }}$ in $O F I$ and $I F I$, respectively. Economically weaker economies tend to rank lower in the two indicators. Effectively, economies that ranked below $30^{\text {th }}$ are all developing economies.

Table 2 Openness Factors and Indigenous Factors Indicators (62 World Economies, 1998-2002 Average)

\begin{tabular}{clclc}
\hline \multirow{2}{*}{ Ranking } & \multicolumn{2}{c}{ Openness Factors Indicator } & \multicolumn{2}{c}{ Indigenous Factors Indicator } \\
\cline { 2 - 5 } & \multicolumn{1}{c}{ Economies } & Index & Economies & Index \\
\hline 1 & Ireland & 1.00 & Sweden & 0.93 \\
3 & United States & 0.70 & Switzerland & 0.91 \\
4 & Netherlands & 0.72 & Finland & 0.90 \\
5 & Switzerland & 0.65 & Denmark & 0.93 \\
6 & Sweden & 0.65 & United States & 0.89 \\
7 & Sinland & 0.62 & Norway & 0.87 \\
8 & Denmark & 0.64 & Canada & 0.88 \\
9 & Austria & 0.61 & Germany & 0.88 \\
10 & United Kingdom & 0.60 & Singapore & 0.86 \\
11 & Canada & 0.60 & Netherlands & 0.84 \\
12 & New Zealand & 0.60 & New Zealand & 0.83 \\
13 & Australia & 0.56 & Austria & 0.86 \\
14 & Norway & 0.50 & United Kingdom & 0.84 \\
15 & Germany & 0.48 & Australia & 0.85 \\
16 & France & 0.49 & Ireland & 0.80 \\
17 & Hong Kong & 0.48 & Spain & 0.74 \\
\hline
\end{tabular}




\begin{tabular}{|c|c|c|c|c|}
\hline 18 & Portugal & 0.40 & Japan & 0.73 \\
\hline 19 & Spain & 0.38 & Portugal & 0.72 \\
\hline 20 & Italy & 0.37 & Hong Kong & 0.71 \\
\hline 21 & Czech Republic & 0.35 & Slovenia & 0.71 \\
\hline 22 & Israel & 0.32 & Italy & 0.70 \\
\hline 23 & Slovenia & 0.30 & Israel & 0.66 \\
\hline 24 & Hungary & 0.27 & Czech Republic & 0.63 \\
\hline 25 & Slovak Republic & 0.28 & Hungary & 0.63 \\
\hline 26 & Japan & 0.27 & Malaysia & 0.53 \\
\hline 27 & Malaysia & 0.26 & Chile & 0.60 \\
\hline 28 & Panama & 0.25 & Greece & 0.59 \\
\hline 29 & Greece & 0.24 & Poland & 0.56 \\
\hline 30 & Poland & 0.23 & Saudi Arabic & 0.52 \\
\hline 31 & Korea & 0.23 & Tunisia & 0.48 \\
\hline 32 & Croatia & 0.20 & Korea & 0.48 \\
\hline 33 & Argentina & 0.19 & Panama & 0.47 \\
\hline 34 & Chile & 0.17 & Slovak Republic & 0.47 \\
\hline 35 & Philippine & 0.16 & Argentina & 0.44 \\
\hline 36 & Brazil & 0.15 & Morocco & 0.41 \\
\hline 37 & Russian & 0.15 & Botswana & 0.43 \\
\hline 38 & Thailand & 0.15 & Brazil & 0.39 \\
\hline 39 & Mexico & 0.14 & Thailand & 0.40 \\
\hline 40 & China & 0.14 & Romania & 0.37 \\
\hline 41 & Turkey & 0.13 & Egypt & 0.36 \\
\hline 42 & Romania & 0.13 & South Africa & 0.38 \\
\hline 43 & South Africa & 0.14 & Croatia & 0.37 \\
\hline 44 & Indonesia & 0.12 & Sri Lanka & 0.34 \\
\hline 45 & Ukraine & 0.12 & Turkey & 0.32 \\
\hline 46 & Botswana & 0.10 & Peru & 0.32 \\
\hline 47 & India & 0.11 & Mexico & 0.30 \\
\hline 48 & Tunisia & 0.11 & Venezuela & 0.30 \\
\hline 49 & Colombia & 0.10 & Colombia & 0.30 \\
\hline 50 & Peru & 0.08 & Russian & 0.29 \\
\hline 51 & Senegal & 0.08 & Philippine & 0.28 \\
\hline 52 & Venezuela & 0.07 & India & 0.26 \\
\hline
\end{tabular}




\begin{tabular}{lllll}
53 & Nigeria & 0.07 & Iran & 0.21 \\
54 & Egypt & 0.07 & China & 0.22 \\
55 & Kenya & 0.06 & Indonesia & 0.16 \\
56 & Morocco & 0.05 & Ukraine & 0.21 \\
57 & Pakistan & 0.05 & Senegal & 0.19 \\
58 & Sri Lanka & 0.04 & Kenya & 0.13 \\
59 & Uganda & 0.04 & Pakistan & 0.12 \\
60 & Saudi Arabic & 0.03 & Uganda & 0.10 \\
61 & Iran & 0.03 & Bangladesh & 0.03 \\
62 & Bangladesh & 0.01 & Nigeria & 0.00 \\
\hline
\end{tabular}

\section{Regression Estimates}

We make use of the two indicators and postulate the hypothesis that economies with strong performance in indigenous factors do enjoy a higher rate of per capita GDP growth at different level of economic openness. We first divide the IFI into $k$ portions using percentiles, shown in Equation (3), with $N$ being the number of economies.

$$
\begin{aligned}
I F I_{t}= & \left\{\min _{i}\{I F I\}, \cdots,((100 / k) \% \times N)^{t h} I F I\right\}_{t},\left\{(((100 / k)+1) \% \times N)^{\text {th }} I F I, \cdots,((2 \times 100 / k) \% \times N)^{t h} I F I\right\}_{t} \\
& , \cdots,\left\{(((\langle k-1\rangle \times 100 / k)+1) \% \times N)^{t h} I F I, \cdots,((k \times 100 / k) \% \times N)^{t h} I F I\right\}_{t} .
\end{aligned}
$$

For example, we can divide the IFI of year $t$ into three portions, so $k=3$, with 33.33 percent of the economies in each portion. The first portion is made up of the minimum IFI in year $t$ to the $33 \mathrm{rd} I F I$ in year $t$. We then assign a dummy variable, $D_{\kappa}$, where $k=1, \ldots, k$, to each of the last $(k-1)$ portions of $I F I$, namely $D_{2}, \cdots D_{k}$. The $D_{k}$ dummy takes a value 
of unity if $I F I_{i t}$ falls into the $\kappa^{\text {th }}$ portion, otherwise it takes a value of zero. Since the $I F I$ is a measure of the indigenous environment of an economy, and the higher the IFI value an economy has, the better is its indigenous environment. Namely, an economy with $D_{\kappa}=1$ has a better indigenous environment than an economy with $D_{\kappa-1}=1$.

We use the following model to examine how indigenous factors can affect the outcome of openness on growth:

$\ln y_{i t}=\alpha+\beta_{1} \ln O F I_{i t}+\beta_{2} \ln O F I_{i t} * D_{2, i t}+\cdots+\beta_{k} \ln O F I_{i t} * D_{k, i t}+\varepsilon_{i t}$,

where $y_{i t}$ is the real GDP per capita deflated by the purchasing power parity of economy $i$ at time $t$. For economy $i$ who has the dummy $D_{\kappa}=1$, the regression equation become:

$\ln y_{i t}=\alpha+\beta_{1} \ln O F I_{i t}+\beta_{\kappa} \ln O F I_{i t}+\varepsilon_{i t}$, or

$\ln y_{i t}=\alpha+\left(\beta_{1}+\beta_{\kappa}\right) \ln O F I_{i t}+\varepsilon_{i t}$.

For another economy $j$ which has the dummy $D_{\kappa-c}=1$, for any $c>0$. In other words, when economy j's indigenous environment is not as good as economy i's, the regression equation become:

$\ln y_{j t}=\alpha+\beta_{1} \ln O F I_{i t}+\beta_{\kappa-c} \ln O F I_{j t}+\varepsilon_{j t}$, or

$\ln y_{j t}=\alpha+\left(\beta_{1}+\beta_{\kappa-c}\right) \ln O F I_{j t}+\varepsilon_{j t}$.

If a higher performance in indigenous factors brings a higher marginal effect of openness on economic growth, we expect to see $\beta_{1}+\beta_{\kappa-c}<\beta_{1}+\beta_{\kappa}$. Thus, 
generalizing all the $k$ dummy variables, and if a better indigenous environment has a positive impact of openness on growth, we expect to see $\beta_{1}<\beta_{1}+\beta_{2}<\beta_{1}+\beta_{3}<\ldots<\beta_{1}+\beta_{k}$, suggesting that a strong performance in an economy's indigenous factors enables an economy to benefit more from openness. We conducted two Wald tests to show the significance of the coefficient estimates. The first Wald test is to see if a low performance in the indigenous factors constrained economic growth. We propose an alternative hypothesis with $\beta_{1}<0$, which implies that if an economy has an extremely weak performance in its indigenous factors (reflected in the IFI value falling into the first partition of the indicator), openness would bring negative effects on economic growth, namely:

$H o^{1}: \beta_{1}=0$

$H a^{1}: \beta_{1}<0$.

The second Wald test shows that an economy's IFI can significantly affect the marginal effect of an economy's openness on its real per capita GDP growth rate:

$H o^{2}: \beta_{1}+\beta_{\kappa}=0$ for $\kappa=2, \cdots, k$.

$H a^{2}: \beta_{1}+\beta_{\kappa-1}<\beta_{1}+\beta_{\kappa}$ for $\kappa=3, \cdots, k$.

The alternative hypothesis, $\mathrm{Ha}^{2}$, states that economies that have a better performance in their indigenous factors should benefit more from openness.

We applied the within-GLS method to estimate Equation (4), but the emergence of the singular matrix problem due probably to the short sample period led us instead to use the pooled-GLS with White-Heteroskedasticity consistent standard error and covariance. 
Equation (4) is estimated with $k=3,4,8$ and 10. Table 3 shows the empirical estimation of the pooled-GLS results for the 62 countries for the sample period of 1998-2002.

Table 3 Pooled-GLS Estimates of 62 World Economies, 1998-2002

\begin{tabular}{|c|c|c|c|c|}
\hline Coefficients & $k=3$ & $k=4$ & $k=8$ & $k=10$ \\
\hline \multirow[t]{2}{*}{$\alpha$} & 7.5159 & 7.3161 & 7.5144 & 7.5269 \\
\hline & $(0.0722)^{*}$ & $(0.0861)^{*}$ & $(0.0967)^{*}$ & $(0.0956)^{*}$ \\
\hline \multirow[t]{2}{*}{$\beta_{1}$} & 0.2904 & 0.3591 & -0.0324 & -0.0868 \\
\hline & $(0.0270)^{*}$ & $(0.0360)^{*}$ & $(0.0911)$ & $(0.0920)$ \\
\hline \multirow[t]{2}{*}{$\beta_{2}$} & 0.3036 & 0.2260 & 0.3593 & 0.3916 \\
\hline & $(0.0073)^{*}$ & $(0.0163)^{*}$ & $(0.0729)^{*}$ & $(0.0739)^{*}$ \\
\hline \multirow[t]{2}{*}{$\beta_{3}$} & 0.3690 & 0.3472 & 0.4956 & 0.5224 \\
\hline & $(0.0097)^{*}$ & $(0.0174)^{*}$ & $(0.0730)^{*}$ & $(0.0731)^{*}$ \\
\hline \multirow[t]{2}{*}{$\beta_{4}$} & & 0.3421 & 0.5961 & 0.5561 \\
\hline & & $(0.0188)^{*}$ & $(0.0750)^{*}$ & $(0.0749)^{*}$ \\
\hline \multirow[t]{2}{*}{$\beta_{5}$} & & & 0.6334 & 0.6447 \\
\hline & & & $(0.0762)^{*}$ & $(0.0759)^{*}$ \\
\hline \multirow[t]{2}{*}{$\beta_{6}$} & & & 0.7027 & 0.6757 \\
\hline & & & $(0.0766)^{*}$ & $(0.0770)^{*}$ \\
\hline \multirow[t]{2}{*}{$\beta_{7}$} & & & 0.6847 & 0.7346 \\
\hline & & & $(0.0777)^{*}$ & $(0.0771)^{*}$ \\
\hline \multirow[t]{2}{*}{$\beta_{8}$} & & & 0.6894 & 0.7523 \\
\hline & & & $(0.0779)^{*}$ & $(0.0782)^{*}$ \\
\hline \multirow[t]{2}{*}{$\beta_{9}$} & & & & 0.7342 \\
\hline & & & & $(0.0787)^{*}$ \\
\hline \multirow[t]{2}{*}{$\beta_{10}$} & & & & 0.7427 \\
\hline & & & & $(0.0788)^{*}$ \\
\hline F-test ${ }^{\dagger}$ & 0.0000 & 0.0000 & 0.0000 & 0.0000 \\
\hline Adj. $R^{2}$ & 0.999704 & 0.999624 & 0.999670 & 0.999745 \\
\hline Wald Test $^{\dagger}$ & 0.0000 & 0.0000 & 0.0000 & 0.0000 \\
\hline
\end{tabular}

Notes: Figures in parentheses are standard errors.

* = significance at $1 \%$ level.

$\dagger=$ significance at $5 \%$ level 
All estimates with $k=3$ and $k=4$ in Table 3 are significant at 1 percent level. In these two cases, the estimate for $\beta_{1}$ is not negative, but is significantly different from zero, suggesting that a low performance in indigenous factors does not adversely affect the effect of globalization on economic growth, though this may be due to the small size of $k$. When the size of $k$ is small, the marginal effect of indigenous factors on globalization and economic growth may not be obvious. The F-tests reject the null hypothesis of Equation (4), and suggests that as economies improve the performance of their indigenous factors, the marginal effect of globalization on growth increases.

For estimates with $k=8$ and $k=10$, and with the exception of the insignificant estimate for $\beta_{1}$, all the estimates are significance at 1 percent level. For these estimated values of $k$, the estimate of $\beta_{1}$ is negative, which means that growth in an economy with low performance in indigenous factors can adversely be affected by globalization. Similar to the results of $k=3$ and $k=4$, the F-tests reject the null hypothesis. This confirms that improvement in the performance of indigenous factors in an economy can improve the marginal effect of globalization on growth.

\section{Optimal Performance in Indigenous Factors}

This section uses a simulation method to work out the optimal performance in the indigenous factors in order to achieve a maximum gain in economic growth. From the estimation result of $k=4,8$ and 10 in Table 3, we first examine economies with top scores 
in IFI to see if there is diminishing returns in economic openness. Hypothetical economies are compared in order to see how an economy performs in growth and globalization given a different level of performance in indigenous factors. We established two hypotheses. First, given two externally homogeneous economies (namely, economies with same performance in the $O F I)$, heterogeneity in the performance of $I F I$ will lead to differences in economic growth and development. Secondly, given homogeneity in the performance of IFI among different economies, those economies with a better performance in $\mathrm{OFI}$ will result in higher economic growth.

We make use of the empirical result with $k=10$ in Table 3 to simulate the growth of GDP per capita for a total of 100 hypothetical economies with an incremental change of 0.01 in the IFI that ranged from zero to one. We set different values of the $O F I$ that are either below or above the median value. A simulated series of per capita GDP figures are generated from the empirical results with $k=10$ in Table $3 .^{7}$ The simulated per capita GDP growth rates are plotted against the IFI, and a step function is presented separately for the four values of $\mathrm{OFI}$ (at $0.25,0.45 .0 .75$ and 0.95 ) as shown in Figure 1.

\footnotetext{
${ }^{7}$ For example, when $O F I=0.25$, and with $D_{3, i t}=1$ (namely, the range of $I F I$ is between 0.2 and 0.3 , and other dummies take a zero value), the simulated GDP per capita growth is 8.92904 (i.e. $7.52687+$ $(-0.08675) * \ln (0.25 * 100)+(0.522359) * \ln (0.25 * 100) * 1)$.
} 


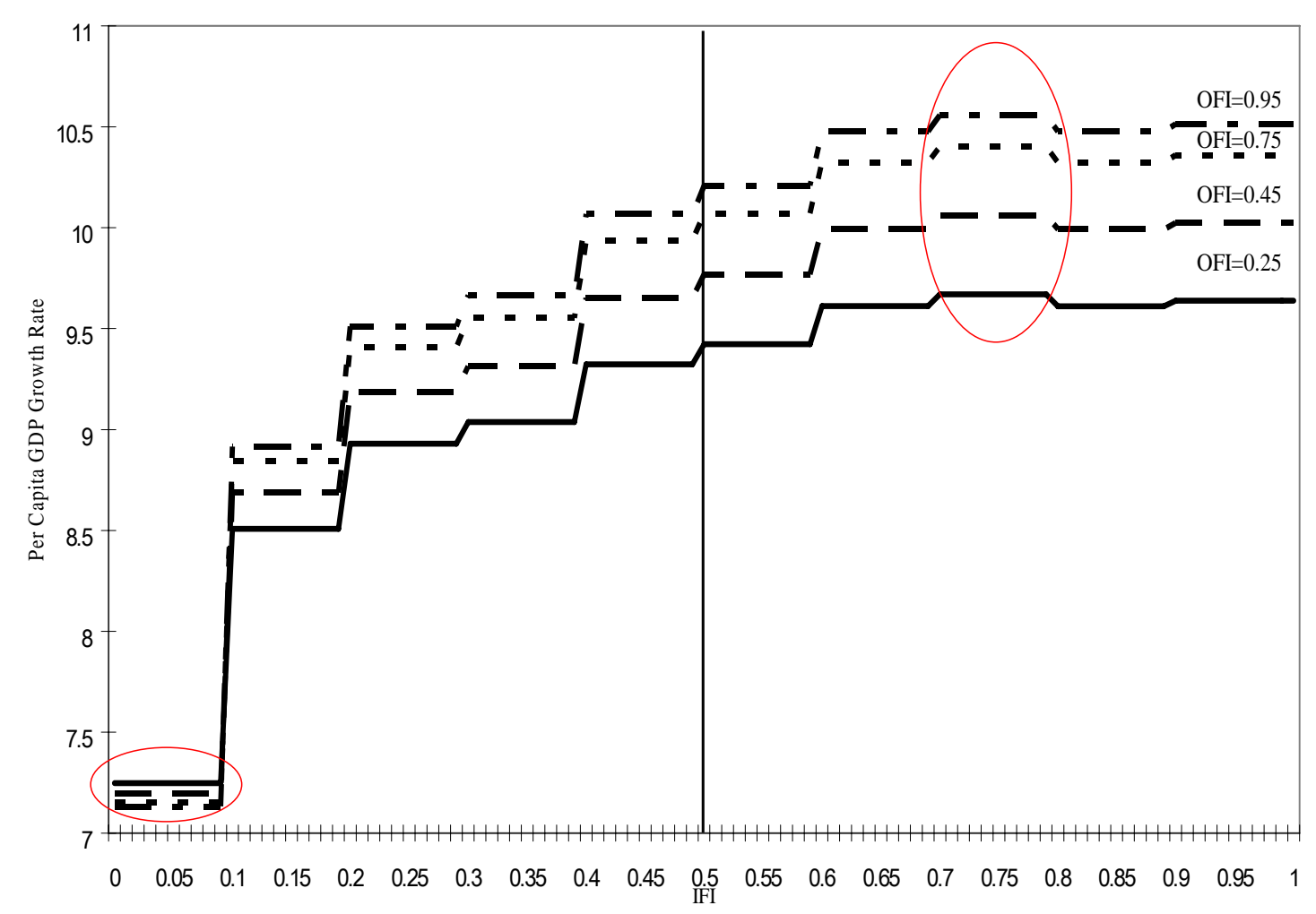

Figure 1 Effect of Economic Openness on Growth

The first observation in Figure 1 is that economies with a higher performance in openness (with higher $O F I$ ) produced a higher level of per capita GDP growth at all level of $I F I$ above 0.1 . In economies with IFI below the median, a higher performance in OFI always produced a higher economic growth measured in GDP per capita, except when $I F I$ is below 0.1 . The second observation is that, when the $I F I$ is above median, economic growth kept rising regardless of the performance in the OFI until an economy's IFI reached the range of 0.7 and 0.8 , beyond which the growth rate of GDP per capita declined. This suggests that the 0.7 to 0.8 range of the $I F I$ is the optimal level, and 
economies will reach their highest possible growth rates given their OFI.

When the value of $O F I$ lies between 0 and 1 , the marginal contribution of $I F I$ to the per capita GDP growth of an economy is positive if the value of IFI lies between 0 and the optimal level. When the value of $I F I$ is above its optimal level, the marginal contribution of IFI to an economy's GDP per capita growth is negative. ${ }^{8}$ In short, if an economy has an IFI value below 0.1 , a lower value of $O F I$ actually produces a higher per capital GDP growth. So long as the value of IFI lies above 0.1 , the marginal contribution by the different level of $O F I$ to per capita GDP growth is positive. On the contrary, when IFI lies between 0 and 0.1 , the marginal contribution of OFI to per capita GDP growth is negative. $^{9}$

The analysis can be extended to examine the marginal effect of both OFI and IFI. By plotting the change in the per capita GDP growth rate against the IFI at different level of the OFI, Figure 2 shows that, at different level of $I F I$, a higher OFI can lead to a larger change in growth rate of per capita GDP. ${ }^{10}$ However, as shown in Figure 3, the marginal effect of IFI on the change in growth rate of per capita GDP at different level of OFI is increasing at a decreasing rate. Furthermore, Figure 3 shows that when the OFI value is

8 This can also be seen if Equation (4) is modeled as a continuous or differentiable function, where $0<i<1$, and $I F I^{*}$ represents the optimal value:

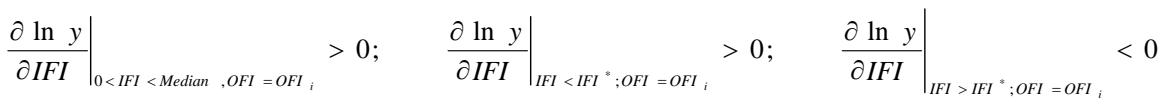

${ }^{9}$ When the function is a differentiable, the results can be summarized as follows:

$$
\left.\frac{\partial \ln y}{\partial \ln O F I}\right|_{0.5<I F I<1}>0 ;\left.\quad \frac{\partial \ln y}{\partial \ln O F I}\right|_{0.1<I F I<0.5}>0 ;\left.\quad \frac{\partial \ln y}{\partial \ln O F I}\right|_{0<I F I<0.1}<0
$$

10 The marginal effect can be summarized as follows when a differentiable equation is used:

$$
\left.\frac{\partial \ln y}{\partial I F I}\right|_{O F \models 0.25}<\left.\frac{\partial \ln y}{\partial I F I}\right|_{O F \models 0.45}<\left.\frac{\partial \ln y}{\partial I F I}\right|_{O F \models 0.75}<\left.\frac{\partial \ln y}{\partial I F I}\right|_{O F=0.95}
$$


below median, the marginal contribution of economic openness towards the economics growth is larger than that when $\mathrm{OFI}$ is above median. ${ }^{11}$

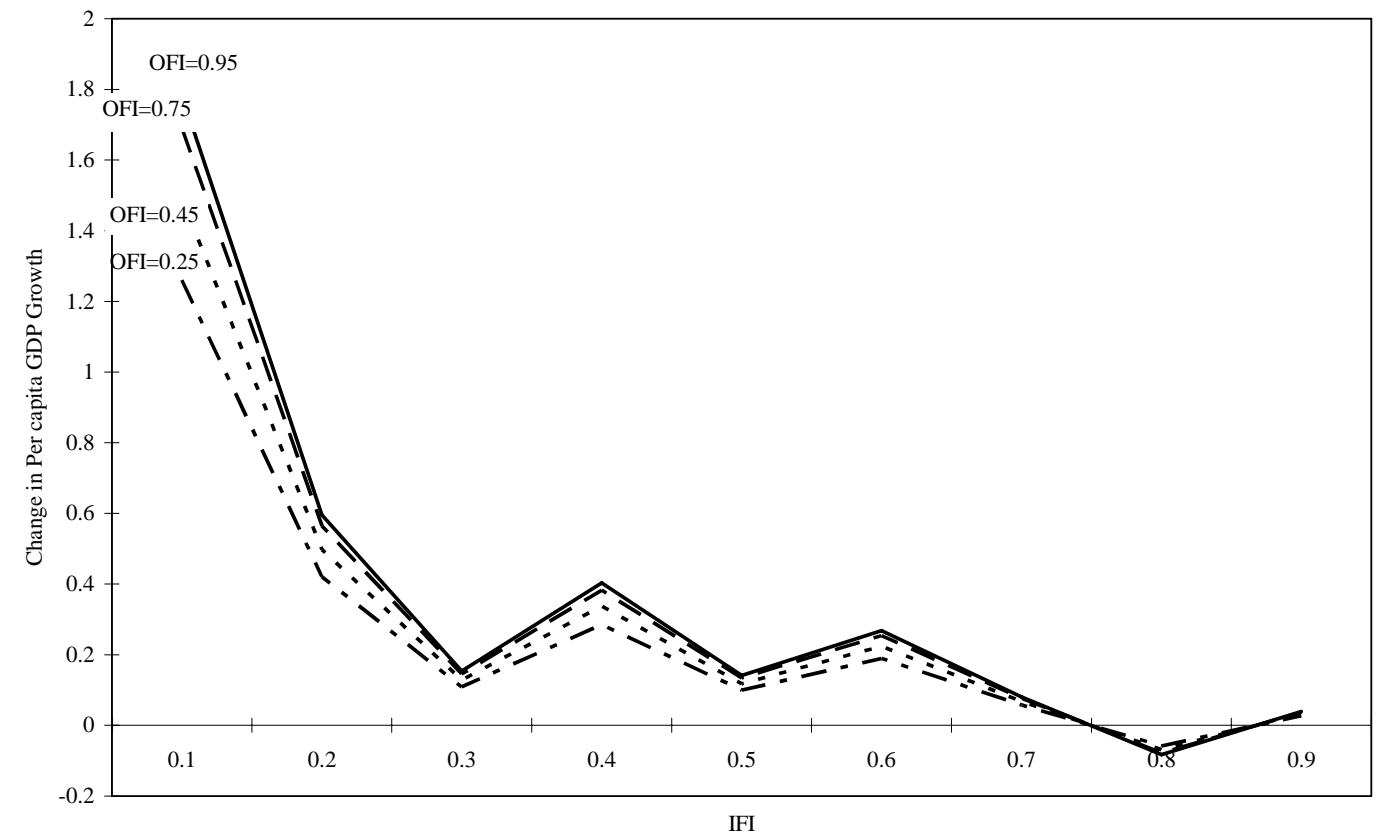

Figure 2 Marginal Effect of OFI on Growth

${ }^{11}$ The marginal effect can be summarized as follows when a differentiable equation is used:

$\left.\frac{\partial \ln Y}{\partial \ln O F I_{\text {Below Median }}}\right|_{I F I=I F I_{i}}>\left.\frac{\partial \ln Y}{\partial \ln O F I_{\text {Above Median }}}\right|_{I F I=I F I_{i}}$ 


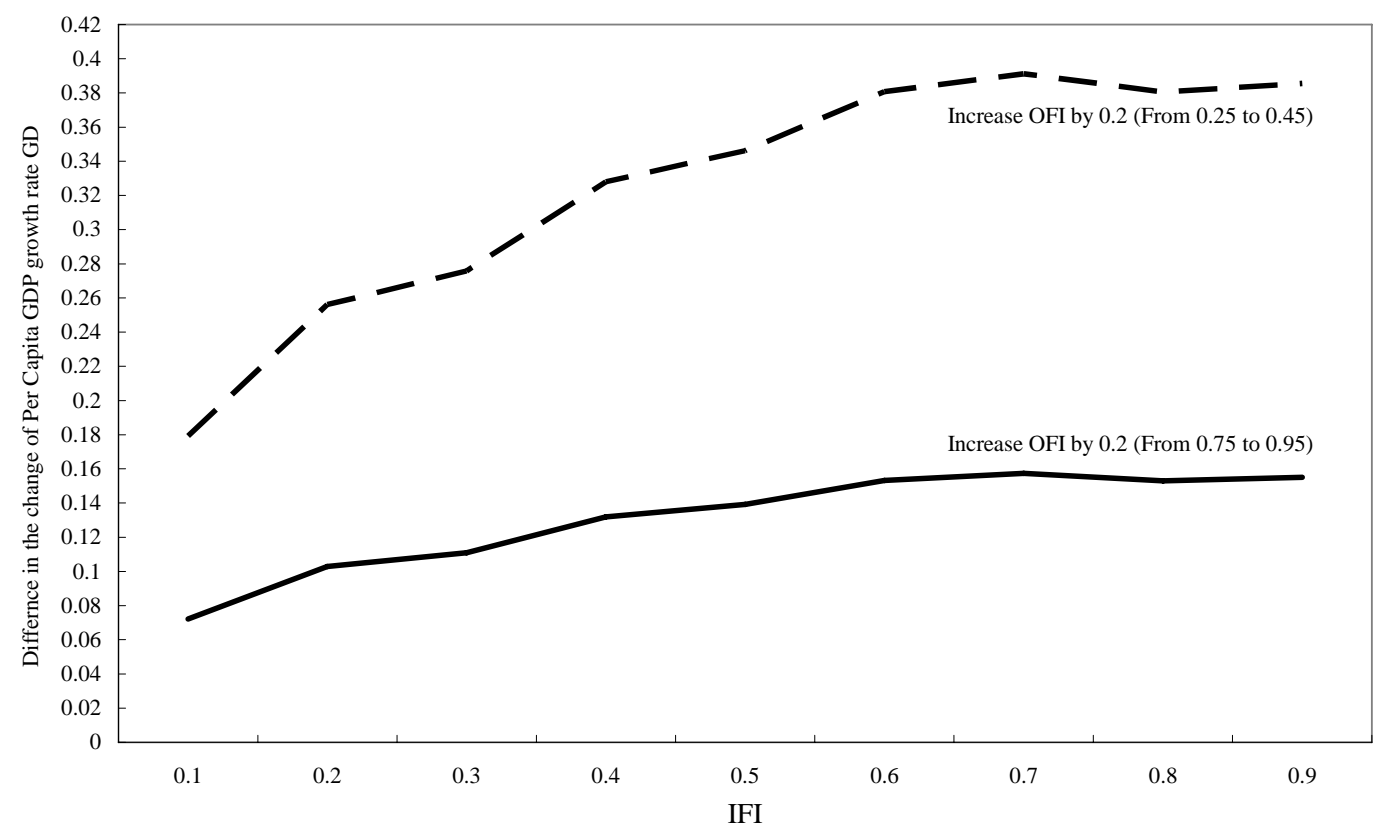

Figure 3 Effect of a Change in OFI

With the construction of the two indicators that look separately at indigenous factors and openness factors, the regression and simulation results provided additional evidence to other studies (for example, Hesmati 2006) that indigenous factors can have independent influence on growth and openness. Various policy recommendations can then be suggested from the empirical and simulation analysis. Firstly, a more globalized economy indicated by the higher performance in economic openness does not always lead to higher economic growth; for those economies with $0<I F I<0.1$, they should improve on the IFI in order to reap additional gain from openness and ultimately globalization. Secondly, economies whose $I F I$ is above 0.1 , but below the optimal range (0.7 to 0.8 ), should aim to improve the performance of the indigenous factors, hoping gradually to reach the optimal level.

A pattern of relationship between economic growth, performance in the openness 
factors and indigenous factors seems to have emerged from the simulation analysis. Figure 4 argues that once the performance in the indigenous factors has reached a minimum level, improvement in indigenous factors will lead to a larger per capita GDP growth rate at every higher level of openness. Thus, at a high level of openness, $\mathrm{OFI}_{3}$ for example, a higher level of per capita GDP growth rate can be achieved.

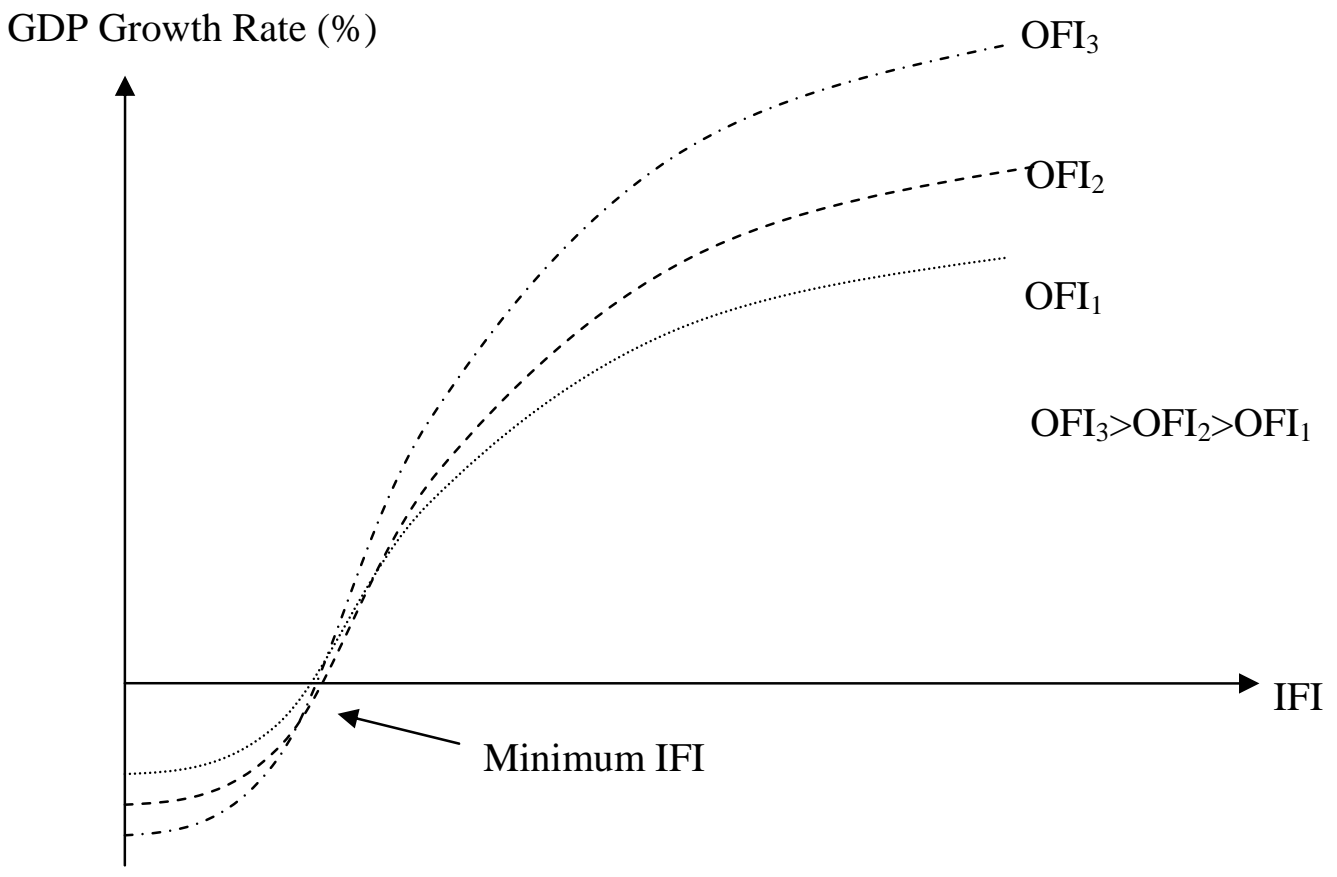

Figure 4 Relationships between Growth, Openness and Indigenous Factors

To see how the 62 world economies perform in the 1998-2002 period, Table 4 maps out the sample period average in five different ranges of OFI and IFI. Individual economies can consider their own positions in the ranking of the two indicators, and compare their performance with other economies, including the periodic average in the GDP per capita growth rates. There are seven mainly poor developing economies (Bangladesh, Indonesia, Kenya, Nigeria, Pakistan, Senegal and Uganda) that have the 
lowest rankings in both indicators. On the contrary, those economies that performed strongly in both $\mathrm{OFI}$ and $I F I$ are mainly developed economies (Austria, Denmark, Finland, Netherlands, Singapore, Sweden, Switzerland, United Kingdom and USA). Most developed economies have performed stronger in IFI than in OFI. Ireland is the only economy that has a stronger performance in $O F I$ than in $I F I$ in the sample period. ${ }^{12}$

The observation from Table 4 is that performance of indigenous factors is the more relevant constraint in the globalization process of any economy. Most economies that are strong in the performance of $I F I$ are also strong in the performance of $O F I$, but not the reverse. In other words, it would be appropriate for economies to improve their indigenous conditions and environment before they can gain from openness and globalization. Economies have to achieve a reasonable level of performance in indigenous factors before gaining the benefits from openness factors. A good performance in indigenous factors is essential to openness, growth and development. There are a number of economies (Argentina, Botswana and so on) that have achieved a median in IFI, but showed low performance in OFI. The 0.61 to 0.80 range of the IFI seems to be the critical range, as virtually all industrially advanced economies achieved an IFI score above 0.61 .

Table 4 shows that a number of economies in the second lowest $(0.21-0.40)$ range of IFI experienced a relative high growth rate in the sample period. For example, China has a growth rate of 6.749 percent and the Russian Federation had 6.381 percent and so on. This suggested that these economies have to improve their IFI before reaping the

\footnotetext{
12 Measured in purchasing power parity constant 2000 price, Ireland's GDP per capita is highest among the 62 world economies.
} 
gain from openness and globalization. Among the developing economies, African economies (e.g. Uganda, Kenya and Senegal) are the weakest performers in both the OFI and IFI, while the middle-ranking economies are the few Asian (e.g. Thailand and Malaysia) and Latin American (e.g. Panama and Chile) economies. Other Asian economies (e.g. India, Indonesia, Philippines and Sri Lanka) performed poorly in both $\mathrm{OFI}$ and IFI. The group of developing economies that have reached the range of $0.61-$ 0.80 in the IFI are mostly Eastern European economies (e.g. Hungary, Slovenia and Czech Republic), which will probably be the next group of countries that would benefit from globalization. The lesson is that sound performance in the various indigenous factors will facilitate good performance of openness factors. In short, advancement in the performance of indigenous factors will help promoting openness. 
Table 4 The OFI - IFI Matrix of World Economies, 1998-2002 Average

\begin{tabular}{|c|c|c|c|c|c|c|c|}
\hline & \multirow[b]{2}{*}{ Range } & \multicolumn{6}{|c|}{ Indigenous Factors Indicator (IFI) } \\
\hline & & $0.00-0.20$ & 0.2 & 0.40 & $0.41-0.60$ & $0.61-0.80$ & $0.81-1.00$ \\
\hline \multirow{21}{*}{ 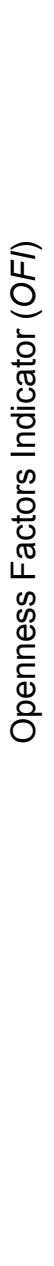 } & \multirow{8}{*}{$\begin{array}{c}0.00- \\
0.20\end{array}$} & Uganda (4.049) & China (6.749) & Philippines (1.239) & Botswana (8.615) & & \\
\hline & & Bangladesh (3.025)* & Russian Fed. (6.381) & Brazil (1.229) & Tunisia (3.198) & & \\
\hline & & Senegal (2.322) & Ukraine (5.692) & S. Africa (1.227) & Thailand (2.911) & & \\
\hline & & Nigeria $(1.575)^{\star}$ & India (3.287) & Mexico (1.001) & Chile (1.072) & & \\
\hline & & Indonesia (1.408) & Romania (3.071) & Peru (0.768) & Morocco (0.720) & & \\
\hline & & Pakistan (1.398) & Egypt (2.932) & Turkey $(-0.096)$ & Saudi Arab. (-0.938) & & \\
\hline & & Kenya $(-1.343)$ & Iran (2.786) & Colombia $(-0.807)$ & Argentina $(-5.887)$ & & \\
\hline & & & Sri Lanka (1.928) & Venezuela $(-3.697)$ & & & \\
\hline & \multirow{8}{*}{$\begin{array}{c}0.21- \\
0.40\end{array}$} & & \multirow{8}{*}{\multicolumn{2}{|c|}{ Croatia (3.654) }} & Korea $(5.957)$ & Hungary (3.869) & \\
\hline & & & & & Greece (4.207) & Slovenia (3.858) & \\
\hline & & & & & Slovak Rep. (3.341) & Czech Rep. (3.354) & \\
\hline & & & & & Poland (2.981) & Spain (2.671) & \\
\hline & & & & & Malaysia (2.945) & Portugal (1.945) & \\
\hline & & & & & Panama (0.661) & Italy $(1.590)$ & \\
\hline & & & & & & Japan (0.477) & \\
\hline & & & & & & Israel (-0.096) & \\
\hline & \multirow{5}{*}{$\begin{array}{c}0.41- \\
0.60\end{array}$} & & & & & Hong Kong (3.346) & New Zealand (3.150) \\
\hline & & & & & & France (2.201) & Canada (2.829) \\
\hline & & & & & & & Australia (1.821) \\
\hline & & & & & & & Norway (1.374) \\
\hline & & & & & & & Germany (1.175) \\
\hline
\end{tabular}




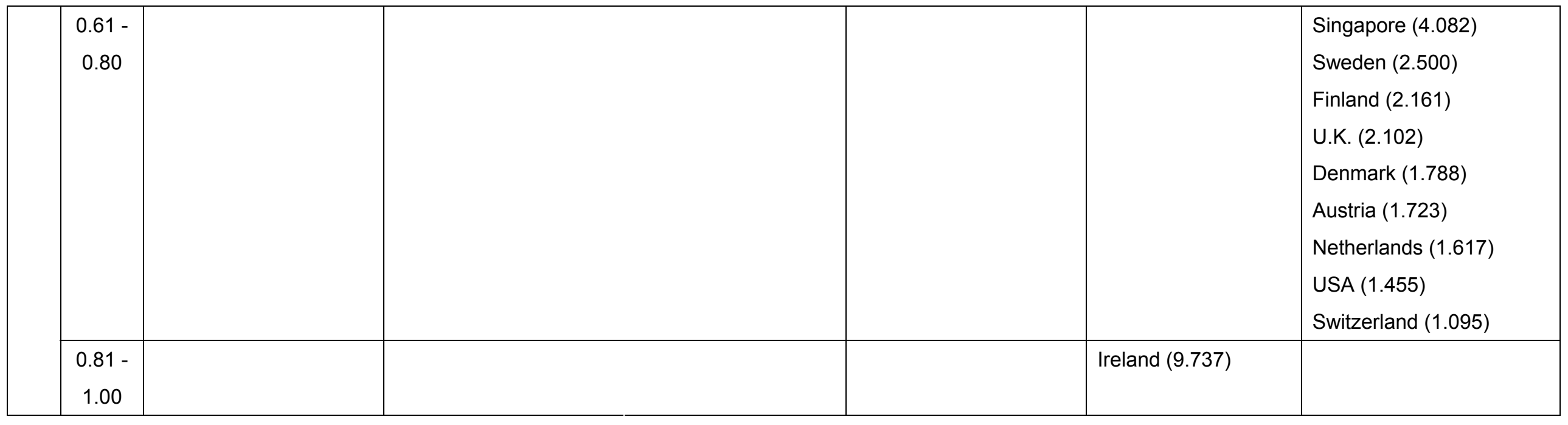

Note: Figures in parenthesis are the percentage growth rates of the average 1999-2002 GDP per capita (purchasing power parity in constant 2000 price).

${ }^{*}$ Countries with $I F I<0.1$ 


\section{Conclusion}

Recent globalization indices ranked the performance of different world economies with few or without the inclusion of domestic or indigenous factors (Anderson and Herbertsson 2005, Kearney 2005 and Dreher 2006). The empirical results in the paper add to the globalization debate and the construction of the globalization index by making reference separately to the relevance and importance of a number of indigenous factors.

In constructing the OFI, this paper takes into account the pattern of trade and industries by incorporating the inter-industry and intra-industry trade, in addition to the total trade flows. The number of indigenous factors used in the construction of IFI should provide a more comprehensive picture on the domestic performance of different economies. The regression result that indigenous factors are important in promoting an economy's growth led to further investigation and analysis on the relationship between the two types of factors. Given different level of performance in the economy's openness, a higher performance in the IFI will produce a higher growth rate. When the performance of an economy's indigenous factors is extremely low, it would be more appropriate for that economy to improve its indigenous factors than to engage in globalization. In short, performance in the indigenous factors is the more fundamental issue than economic openness. Before the "optimal" level of indigenous factors performance is reached, the economy will get better off in per capita GDP as the performance of indigenous factors improve.

Literature on the gain from globalization points to the importance of a sound performance in domestic factors. By comparing the 62 world economies in their 
performance in both the openness and indigenous factors, one comes to the conclusion that sound performance in the indigenous factors is very crucial to economic openness and globalization. All economies with strong performance in economic openness and globalization have sound performance in their indigenous factors. For those world economies that are ranked low in the IFI, appropriate economic policies should be conducted to improve the performance of different indigenous factors. 


\section{References}

Aisbett, E. (2005) Why are the Critics so Convinced that Globalization is Bad for the Poor?, Working Paper No. 11066, National Bureau of Economic Research.

Andersen, T., and Herbertsson, T. (2005) Quantifying Globalization, Applied Economics, 37, pp. 1089-1098.

Balassa, B. (1965) Traded Liberalization and 'Revealed' Comparative Advantage, The Manchester School of Economic and Social Studies, 33, pp. 99-123.

Balassa, B. (1977) Revealed' Comparative Advantage Revisited: An Analysis of Relative Export Shares of the Industrial Countries, 1953-1971, The Manchester School of Economic and Social Studies, 45, pp. 327-344.

Balassa, B. (1979) The Changing Pattern of Comparative Advantage in Manufactured Goods, Review of Economics and Statistics, 61(2), pp. 259-266.

Balassa, B. (1986) Comparative Advantage in Manufactured Goods: A

Reappraisal, Review of Economics and Statistics, 68(2), pp. 315-319.

Bhagwati, J. (2002) Free Trade Today, (Princeton: Princeton University Press).

Bhagwati, J. (2004) In Defense of Globalization, (New York: Oxford University Press).

Central Intelligent Agency, (1998-2002) The World Factbook. (Washington D C: Central Intelligent Agency).

Deardorff, A., and Stern, R. (2002) What You Should Know about Globalization and the World Trade Organization, Review of International Economics, 10 (3), pp. 404-423.

Dreher, A. (2006) Does Globalization Affect Growth? Evidence from a New Index of Globalization, Applied Economics (forthcoming).

Edmonds, E., and Pavcnik, N. (2002) Does Globalization Increase Child Labor?

Evidence from Vietnam, Working Paper 8760, National Bureau of Economic Research.

Falvery, R., and Kreickemeier, E. (2005) Globalization and Factor Returns in Competitive Markets, Journal of International Economics, 66, pp. 233-248.

Feldstein, M. (2000) Aspects of Global Economic Integration: Outlook for the Future, Working Paper 7899, National Bureau of Economic Research.

Fischer, S. (2003) Globalization and Its Challenge, Ely Lecture, American Economic Association Meeting, Washington D C, January. 
Frankel, J. (2000) Globalization of the Economy, Working Paper 7858, National Bureau of Economic Research.

Heritage Foundation, (1998-2002) Index of Economic Freedom, (Washington D C: Heritage Foundation).

Heshmati, A. (2006) Measurement of a Multidimensional Index of Globalization, Global Economy Journal, 6 - 2 Article 1.

International Telecommunication Union, (1998-2002) International

Telecommunication Union Database, (Geneva: International

Telecommunication Union).

International Telecommunication Union, (1998-2002) Netcraft Secure Server

Surveys, (Geneva: International Telecommunication Union).

International Monetary Fund, (1998-2002) International Financial Statistics,

(Washington D C: International Monetary Fund).

Kearney, A. (2005) Measuring Globalization: Economic Reversals, Forward

Momentum, (Washington D C: Foreign Policy).

Lockwood, B. (2004) How Robust is the Foreign Policy-Kearney Globalisation

Index?, The World Economy, 27, pp. 507--523.

Rencher, A. (2002) Methods of Multivariate Analysis, Second Edition, (New York:

Wiley-Interscience).

Stiglitz, J. (2002) Globalization and Its Discontent, (London: Allen Lane).

Subramanian, A., and Wei, S. (2003) The WTO Promotes Trade, Strongly but

Unevenly, Working Paper 10024, National Bureau of Economic Research.

Transparency House, (2003) Corruption Index 1996-2002, (Washington D C:

Transparency House).

United Nations, (1998-2002) Balance of Payments Statistics, (New York: United Nations).

United Nations, (1998-2002) United Nations Development Program Indicators,

(New York: United Nations).

United Nations, (1998-2002) United Nations Comtrade, (New York: United

Nations).

Wallach, L., and Woodall, P. (2004) Whose Trade Organization, (New York: The New Press).

Winters, L. (2002) Trade Policies for Poverty Alleviation, in Hoekman, B. Mattoo, A. and English, P. (Eds.), Development, Trade and the WTO: A Handbook, (Washington D C: The World Bank).

World Bank, (1998-2002) Aggregate Governance Indicators, (Washington D C: 
World Bank).

World Bank, (1998-2002) World Development Indicators, (Washington D C: World Bank).

World Tourism Organization, (1998-2002) Compendium of Tourism Statistics, (New York: United Nations). 


\section{$\underline{\text { CSGR Working Paper Series }}$}

189/06, January Amrita Dhillon, Javier Garcia-Fronti, Sayantan Ghosal and Marcus Miller

Bargaining and Sustainability: The Argentine Debt Swap

190/06 January Marcus Miller, Javier Garcia-Fronti and Lei Zhang

Contractionary devaluation and credit crunch: Analysing Argentina.

191/06 January Wyn Grant

Why It Won’t Be Like This All The Time: the Shift from Duopoly to Oligopoly in

Agricultural Trade

192/06 January Michael Keating

Global best practice(s) and electricity sector reform in Uganda

193/06 February Natalie Chen, Paola Conconi and Carlo Perroni

Does migration empower married women?

194/06 February Emanuel Kohlscheen

Why are there serial defaulters? Quasi-experimental evidence from constitutions.

195/06 March Torsten Strulik

Knowledge politics in the field of global finance? The emergence of a cognitive approach in banking supervision

196/06 March Mark Beeson and Hidetaka Yoshimatsu

Asia’s Odd Men Out: Australia, Japan, and the Politics of Regionalism

197/06 March Javier Garcia Fronti and Lei Zhang

Political Instability and the Peso Problem

198/06 March Hidetaka YOSHIMATSU

Collective Action Problems and Regional Integration in ASEAN

199/06 March $\quad$ Eddy Lee and Marco Vivarelli

The Social Impact of Globalisation in the Developing Countries. 
200/06 April

201/06 April

203/06 April

204/06 April

205/06 April

207/06 May

209/06 June

208/06 May
Jan Aart Scholte

Political Parties and Global Democracy

Peter Newell

Civil society participation in trade policy-making in Latin America: The Case of the

Environmental Movement

Marcus Miller and Dania Thomas

Sovereign Debt Restructuring: The Judge, the Vultures and Creditor Rights

Fondo Sikod

Globalisation and Rural Development in Africa: The Case of the Chad-Cameroon Oil Pipeline.

\section{Gilles Quentel}

The Translation of a Crucial Political Speech: G.W.Bush’ State of the Union Address 2003 in Le Monde

Paola Robotti

Arbitrage and Short Selling: A Political Economy Approach

\section{T.Huw Edwards}

Measuring Global and Regional Trade Integration in terms of Concentration of Access

Dilip K. Das

Development, Developing Economies and the Doha Round of Multilateral Trade Negotiations

\section{Alla Glinchikova}

A New Challenge for Civic National Integration: A Perspective from Russia.

Celine Tan

Who’s 'Free Riding'? A Critique of the World Bank’s Approach to Non-Concessional Borrowing in Low-Income Countries 
210/06 September Richard Higgott

International Political Economy (IPE) and the Demand for Political Philosophy in an Era of Globalisation

211/06 October Peter Waterman

Union Organisations, Social Movements and the Augean Stables of Global Governance

212/06 October Peter Waterman and Kyle Pope

The Bamako Appeal of Samir Amin: A Post-Modern Janus?

213/06 October Marcus Miller, Javier García-Fronti and Lei Zhang

Supply Shocks and Currency Crises: The Policy Dilemma Reconsidered

214/06 December Gianluca Grimalda

Which Relation between Globalisation and Individual Propensity to Co-Operate?

Some Preliminary Results from an Experimental Investigation

215/07 January Kui-Wai Li, Iris A.J. Pang and Michael C.M. Ng

Can Performance of Indigenous Factors Influence Growth and Globalisation?

\section{Centre for the Study of Globalisation and Regionalisation}

University of Warwick

Coventry CV4 7AL, UK

Tel: +44 (0)24 76572533

Fax: +44 (0)24 76572548

Email: csgr@warwick.ac.uk

Web address: http://www.csgr.org 